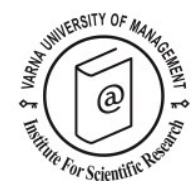

\title{
An analysis of online reviews by language groups: the case of hotels in Porto, Portugal
}

\author{
Luís Pacheco ${ }^{1 *}$
}

Received: 04/11/2015 Accepted: 26/04/2016

\footnotetext{
1 Universidade Portucalense, Portucalense Institute for Legal Research - IJP, room 201, Rua Dr. António Bernardino de Almeida, 541-619, 4200-072 Porto, Portugal; tel: +351 225572000; fax: +351 225572010; email: luisp@upt.pt

* Corresponding author
}

\begin{abstract}
Electronic word-of-mouth has gained importance with the emergence of new online tools and the hospitality sector is at the core of that phenomenon. In this paper we employ a secondary data set of hotel guest reviews for Porto, Portugal, star-rated hotels on a large online travel platform, to explore the distribution and difference in rating behavior of English, Portuguese, Spanish, French and Brazilian guests in an online environment. We find that hotels should promote greater participation by customers in online review platforms, since the average review rating tends to increase with the number of reviews. In terms of language groups, we find that Brazilian travelers tend to give higher ratings and that Spanish travelers are at the other end of the spectrum. Also, low-class hotels are more likely to have customer satisfaction differences, whereas upgrading from a four to a five-star hotel yields a slight boost in ratings. Our results point out that special attention should be given to Spanish guests in all hotel classes, but particularly in middle and low-class hotels. These hotels should be more attentive towards their Spanish guests, exerting more effort to satisfy them in order to obtain better online ratings.
\end{abstract}

(C) 2016 Varna University of Management. All rights reserved

Keywords: electronic word-of-mouth, online review platforms, hotels, satisfaction differences, Portugal

Citation: Pacheco L. (2016) An analysis of online reviews by language groups: the case of hotels in Porto, Portugal. European Journal of Tourism Research 14, pp. 66-74

\section{Introduction}

Online reviews, ratings or opinions, as part of the Electronic word-of-mouth (eWOM) phenomenon, have gained importance with the emergence of new technology and tools. Litvin et al. (2008) define eWOM as "all informal communications directed at consumers through Internet-based technology related to the usage or characteristics of particular goods and services, or their sellers". As stated by Cantallops and Salvi (2014, p. 41), the main differences between WOM and eWOM can be identified in the reach of the reviews' impact (number of people who can be influenced) and the speed of interaction (Litvin et al., 2008; Cox et al., 2009). 
Portugal stands at $15^{\text {th }}$ out of 141 countries in the "Travel \& Tourism Competitiveness Index 2015" (TTCl, 2016) and particularly the city of Porto, located in the North of Portugal, has become a success story in terms of a travel destination in the past decade. In recent years the city has been selected as the "Best European destination" and one of the most romantic and traditional cities in Europe by several specialized travel publications and sites. The number of tourists and hotel stays has been steadily increasing, as well as the number of hotels and available beds amidst a surge of urban rehabilitation of Porto's "World Heritage" historical center. Data for the entire northern region of Portugal show that in 2014 the region attracted more than two and a half million stays in hotels, $55 \%$ of them from foreigners (mostly from Spain, France, the United Kingdom and Brazil).

The objective of this paper is to study the relationship between online hotel reviews and the language used in those reviews, testing whether five different nationalities tend to have significantly different hotel ratings. The data were obtained from a large online travel platform, TripAdvisor, where more than 160 new contributions are posted every minute (URL: www.tripadvisor.com). The analysis and comparison of opinions of different language groups is completely new in the Portuguese context and we expect that our results highlight some differences between language groups, providing insights for hotel managers' efforts in terms of customer satisfaction.

The next section presents a literature review and the subsequent sections present the data and methodology and the results. The fifth section presents a discussion of the results and the paper ends with some concluding remarks.

\section{Literature review}

Distinct cultural backgrounds lead to different consumption concepts, perceived satisfaction and ratings (Ayoun and Moreo, 2008; Chen et al., 2012). In this paper we aim to investigate whether travelers from different cultural backgrounds, which are proxied in terms of spoken languages, rate hotels significantly different. There are several studies that focus on the relationship of these cultural factors with hotel satisfaction (Huang et al., 1996; Tse and Ho, 2009; Hsieh and Tsai, 2009, among others or Schuckert et al., 2014, for a literature review).The majority of studies use only a few hotels and a few hundred respondents obtained through questionnaires whereas our study uses secondary data obtained from a large set of reviews for all the star-rated hotels in the Porto area, analyzing 2150 customer ratings.

Web 2.0 technologies have changed the ways users search and share information, offering new ways of communication that enable users to share their opinions with all other users in an efficient, instantaneous platform and without time or geographical limitations. The influence of eWOM is directly applicable to tourism and hospitality, since user-generated reviews are an important source of information for prospective travelers searching for independent evaluations. Indeed, its influence is particularly high for experience goods such as in the hospitality and tourism context, because quality is only perceived after consumption, (Ye et al., 2009; Lopes et al., 2014). Additionally, people tend to trust information more when it comes directly from other consumers, supposedly helping them to avoid inadequate choices (Stringam et al., 2010; Ye et al., 2011). Research by Lu and Stepchenkova (2012) indicates that almost all respondents read online comments while planning their trips and they believe those online comments are more likely to contain updated, detailed and trustworthy information (Yoo and Gretzel, 2008; Vermeulen and Seegers, 2009; Xiang and Gretzel, 2010). A particularly important issue for the hotel industry is that research indicates that people pay greater attention to criticisms or negative reviews than to positive reviews (Lee et al., 2008; Sparks and Browning, 2011). However, due to the increasing use of social media, online review platforms and other usergenerated content, there is a danger of consumers feeling flooded with information, in an eWOM overload (Park and Lee, 2008). Also, notice that it is difficult for a consumer to determine the credibility of a message coming from strangers. Concerning the fear that usergenerated contents can be jeopardized by fake comments made under the cover of anonymity, O'Connor (2010) argues that such fear is 
An analysis of online reviews by language groups: the case of hotels in Porto, Portugal.

baseless since research has found little evidence of fake reviews, only residual cases. But for this reason many online intermediaries - including TripAdvisor - require reviewers to register and provide some additional personal information including name, residence, nationality or gender (Jeong and Jeon, 2008; Xie et al., 2011). The motives for users to post reviews have been researched by several authors (Zheng et al., 2009; Huang et al., 2010; Wilson et al., 2012). For instance, Zheng et al. (2009) suggest that negative experiences are more likely to motivate dissatisfied consumers to post reviews. Some research argues that there is an inverted- $U$ relationship between customer satisfaction and quantity of WOM or eWOM, with customers who are neither extremely satisfied nor unsatisfied sharing their experiences less (Bansal and Voyer, 2000; Litvin et al., 2008). Cantallops and Salvi (2014), present a complete survey, reviewing papers on eWOM published in the period 2007-2011 and end their paper with some suggestions for future avenues of research on the subject. Those authors conclude that previous research could be grouped into two general lines of work: factors related to the generation of comments and the impact those comments have on consumers and on company perspectives.

Some previous studies used TripAdvisor or other sites as a source of data, collecting the data either manually or automatically (Gerdes and Stringam, 2008). Not trying to be exhaustive here, one example is Jeong and Jeon (2008) who explored how consistent the posted reviews were with the expected level of service and room rate. Examining guests' reviews of hotels in New York City posted on TripAdvisor, their results indicated that value is one of the key predictors for guest satisfaction, which leads to return intentions. Regardless of hotel class and average daily rate (ADR), location appears to have the highest mean value among seven performance attributes and hotel classes (i.e., number of stars) and ADR appears to influence the relationships of selected hotel performance attributes with both overall guest satisfaction and return intentions. Using the largest travel website in China, Ye et al. (2009) conducted a study to empirically investigate the impact of online consumer- generated reviews on hotel room sales, by tallying the number of reviews received on a travel website which they consider to be a proxy of room sales. Their results indicated a significant relationship between online consumer reviews and business performance of hotels, with an increase of the variance in ratings given by customers diminishing hotel room ratings. Stringam et al. (2010) studied the relationship between the overall satisfaction of guests with hotel services, the condition of hotels, cleanliness of rooms and room comfort. Their study looked at over 60,000 traveler ratings, and the majority of all four quality ratings and overall satisfaction were positive. Additionally, nearly $75 \%$ of responses indicated willingness to recommend the hotel. All four quality ratings were found to have similarly strong associations with travelers' overall rating and willingness to recommend. Partial correlations differed, with hotel service and room comfort being the highest, followed by hotel condition and room cleanliness. Stringam and Gerdes (2010) evaluated 60,648 consumer ratings and comments from an online distribution site to explore what factors drive consumer ratings of hotels. Specifically, the paper yields information about the most frequently used words, as well as the pattern of word usage with either high or low guest ratings. It also explored the word choices of hotel guests assigning lower ratings versus higher ratings. Lee et al. (2011) profiled guests who post helpful reviews in TripAdvisor. The key finding is that helpful reviewers are those who travel more, actively post reviews, belong to any age and gender groups, and give lower hotel ratings. Following previous work from Jeong and Jeon (2008) and Stringam et al. (2010), Limberger et al. (2014) also sought to identify the correlation between overall satisfaction and the evaluation criteria used on TripAdvisor, analyzing 660 reviews for overall satisfaction, value, location, sleep quality, rooms, cleanliness and service. Applying a method of multivariate analysis, their results showed a strong correlation of overall satisfaction with the room, service provided and location. Wilson et al. (2012) examined the influence of nationality both on the motivation to post (or not) and on where and what type of content consumers share in the context of a recent trip. The method used was an online 
survey of 568 respondents located in Switzerland, the United Kingdom, and Spain and the results revealed differences in national attitudes and motivations for posting. Respondents in Switzerland and the United Kingdom were more likely to post photos or travelogues on Facebook, but respondents from Spain preferred to post on TripAdvisor with the goal of making recommendations to other travelers. The authors concluded that people from different countries have diverse reasons for posting, and hotel managers must take into account the differences in posting behaviors. Chaves et al. (2012) collected 1500 online reviews from 50 small and medium Portuguese hotels from Booking.com and TripAdvisor. Their study shows that the room, staff and location were the criteria which appeared more frequently in the reviews, thus highlighting aspects that hotel managers should prioritize. Considering both the content of reviews and the volume of eWOM in a broad sample of 16,680 hotels, Melián-González et al. (2013) found a relationship between valence (positive vs. negative posts) and volume, in the sense that initial hotel reviews tend to be disproportionately negative. As hotels receive more reviews, their average ratings improve and the standard deviation declines, which means there is a greater agreement in ratings and the negative effects are mitigated. One implication of their study is that hotel managers should try to increase the number of reviews they receive to balance the positive and negative opinions about their property. Later we will return to this issue. Finally, a recent paper by Jiang et al. (2014) analyzed reviews posted on TripAdvisor by English-speaking travelers about hotels in Mainland China. The authors compared brand image across hotel types and star rating levels, finding that brand image varied based on specific hotel characteristics, emphasizing different areas of service. For instance, the authors found that a certain star level does not necessarily mean a predetermined type of review, a feature that highlights the importance to distinguish ratings between star levels.

In this exploratory paper we follow and develop the paper from Schuckert et al. (2015), which explored the distribution and rating behavior of English and non-English speaking guests, analyzing not only global rates but every aspect of hotel satisfaction (e.g., value, location, etc.). Those authors found that English speaking guests prefer high-class hotels and non-English speaking guests are more fastidious about fivestar hotels and demand higher service quality. Also, the levels of satisfaction differ more in lower class hotels.

\section{Data and methodology}

The data used in this study were retrieved manually from TripAdvisor, one of the most popular travel websites. TripAdvisor has a mechanism that enables users to input reviews for their hotel stays and share experiences, posting classifications from 1 (very unsatisfied/terrible) to 5 (very satisfied/excellent). These scores represent eWOM in a straightforward manner. Table 1 presents the data available in TripAdvisor concerning hotels in the Porto area and the data set that will be used in this study.

The data collection was conducted in October 2015 and the sample of hotels was chosen based on the following criteria: i) the hotel must have at least 100 reviews; ii) the hotel must have at least 10 review ratings written in each of the languages analyzed: English, Portuguese, French, Spanish and PortugueseBrazilian; iii) all the reviews must be less than one year old. After applying these criteria we obtained a sample of 43 hotels, distributed in different categories and comprising 2,150 review ratings (Table 1 ).

Notice that the use of a certain language is not coincident with geographic boundaries or certain nationalities, but here we hypothesize that the users of a certain language, independent of their nationality, share a common set of cultural backgrounds and norms. Also, to distinguish between Portuguese-Brazilian and Portuguese reviews we considered the location of the reviewer. Finally, we limited the number of analyzed reviews to 10 per language due to data availability. Nevertheless, previous studies suggest that customers rarely read online comments beyond the first or second page, giving thus preference to recent reviews (Pavlou and Dimoka, 2006; Sparks and Browning, 2011). Previous to the different 
Table 1. Data set

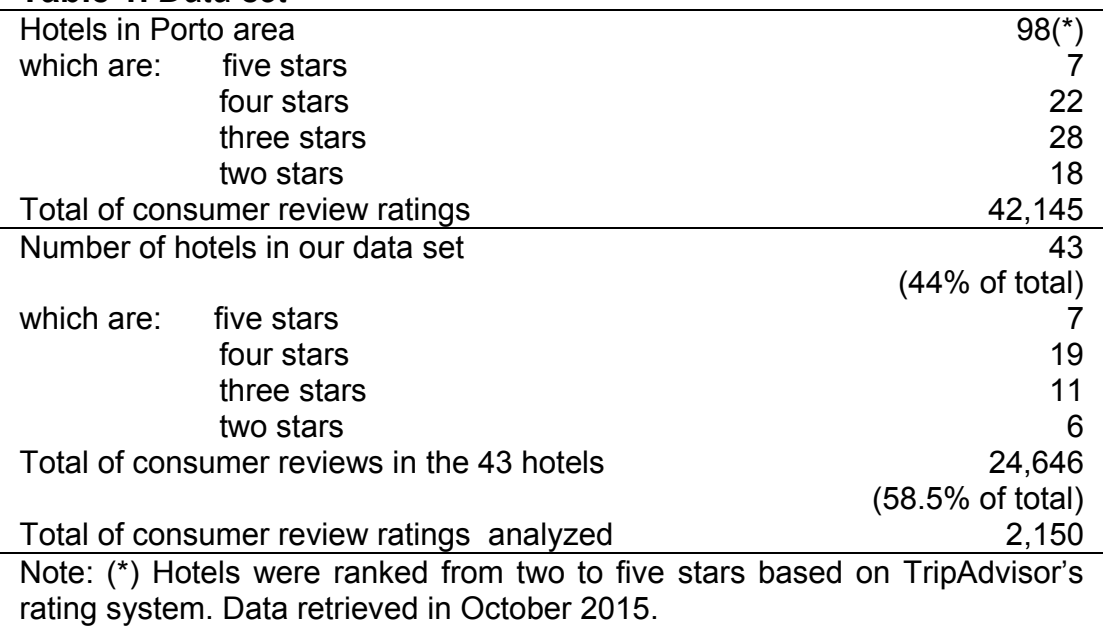

Table 2. Means and standard deviations

English Portuguese Spanish French Brazilian $\begin{gathered}\text { Overall } \\ \text { mean }\end{gathered}$

\begin{tabular}{lllllll} 
Mean & & & & & & \\
Total & 3.97 & 4.00 & 3.87 & 3.94 & 4.20 & 4.00 \\
$\mathbf{5}^{*}$ & 4.26 & 4.37 & 4.40 & 4.20 & 4.53 & 4.35 \\
$\mathbf{4}^{*}$ & 4.07 & 4.14 & 3.99 & 4.01 & 4.26 & 4.09 \\
$\mathbf{3}^{*}$ & 3.67 & 3.72 & 3.58 & 3.74 & 4.10 & 3.76 \\
$\mathbf{2}^{*}$ & 3.90 & 3.67 & 3.35 & 3.80 & 3.82 & 3.71 \\
\hline Standard deviation & & & & & & \\
Total & 1.00 & 0.93 & 1.00 & 0.87 & 0.80 & 0.93 \\
$\mathbf{5}^{*}$ & 0.96 & 0.95 & 0.81 & 0.79 & 0.70 & 0.85 \\
$\mathbf{4}^{*}$ & 0.85 & 0.87 & 0.86 & 0.88 & 0.73 & 0.85 \\
$\mathbf{3}^{*}$ & 1.14 & 0.89 & 1.03 & 0.88 & 0.85 & 0.98 \\
$\mathbf{2}^{*}$ & 1.08 & 0.91 & 1.18 & 0.80 & 0.87 & 0.99 \\
\hline
\end{tabular}

Note: $n=430$ for each language and $n=2,150$ for the overall mean.

Table 3. Correlation matrix

\begin{tabular}{lccccc}
\hline & English & Portuguese & Spanish & French & Brazilian \\
English & 1 & & & \\
Portuguese & $0.206\left(^{* * *}\right)$ & 1 & & \\
Spanish & $0.213\left(^{* * *}\right)$ & $\left.0.1811^{* * *}\right)$ & 1 & & \\
French & $0.100\left(^{* *}\right)$ & $0.135\left(^{* *}\right)$ & $0.165\left(^{* * *}\right)$ & 1 & \\
Brazilian & $0.105\left(^{* *}\right)$ & $\left.0.1811^{* * *}\right)$ & $0.162\left(^{* * *}\right)$ & $0.151\left(^{* *}\right)$ & 1 \\
\hline Note: ${ }^{*} p<0.05 ;{ }^{* *} p<0.01$ and ${ }^{* * *} p<0.001$. & & & &
\end{tabular}

languages tests we will also test the MeliánGonzález et al. (2013) hypothesis that average ratings depend positively on the number of customers who submit reviews. A confirmation of that hypothesis would highlight the importance for hotels to promote greater 70 participation of customers in online review platforms.

\section{Results}

Our research focuses on three points: i) whether the average rating that hotels receive 
depends positively on the number of reviews (and its variance); ii) whether there are differences in reviews posted in different languages; iii) whether those differences are related to the hotel classification. Table 2 presents the means and standard deviations of the different reviews, either in global terms or in terms of hotel ranking.

Table 3 presents the correlation matrix for total reviews in different languages.

To test the first hypothesis we perform a simple OLS regression for the 43 hotels, of the hotel's average score against the number of reviews and its variance (computed for the 50 reviews considered per hotel):

$Y_{i}=$ constant $+\beta_{1} X 1_{i}+\beta_{2} X 2_{i}+\varepsilon_{i}$

where: $Y_{i}$ - Dependent variable (average rating for the $i$-th hotel); $\beta$ - Coefficient to estimate; $X_{i}$ - Independent variables for the $i$-th hotel (X1: number of reviews; $\mathrm{X} 2$ : variance of review ratings); $\varepsilon_{i}$ - error describing the nonexplained effects on $Y_{i}$. Table 4 presents the results obtained for the regression.

To test the remaining two hypotheses we ran ttests to determine whether there are differences in means among different languages, comparing English reviews with Portuguese, Spanish, French, PortugueseBrazilian and vice-versa. This comprises a total of 10 combinations and Table 5 reports the results, differentiating between hotel classes.

\section{Discussion}

As can be seen in Table 2, mean values tend to decrease with lower hotel rankings as expected. This appears in all languages, with some exceptions for the 2-star hotels. Also, Brazilians seem to post consistently better reviews, whereas Spanish travelers to Porto are more demanding. The fact that all the ratings increase as we go from lower to

Table 4. Regression results

\begin{tabular}{lcc}
\cline { 2 - 3 } & Coefficient & Sig \\
\hline Constant & 4.2248 & ${ }^{* * *}$ \\
Number of reviews & 0.00043 & $* *$ \\
Variance of review ratings & -0.56739 & $* * *$ \\
$\mathrm{R}^{2}$ & 0.46 & \\
$\mathrm{R}^{2}$ adjusted & 0.43 & \\
$\mathrm{~F}$ & 25.94 & $* * *$ \\
\hline
\end{tabular}

Note: ${ }^{*} p<0.05 ;{ }^{* *} p<0.01$ and ${ }^{* * *} p<0.001$.

Table 5.T-test results for differences in review ratings

\begin{tabular}{|c|c|c|c|c|c|}
\hline & & & t-statistic & & \\
\hline & Total & $5^{*}$ & $4^{*}$ & $3^{*}$ & $2^{*}$ \\
\hline English-Portuguese & 0.424 & 0.708 & -0.774 & -0.329 & 1.274 \\
\hline English-Spanish & -1.602 & 0.955 & 0.839 & 0.621 & 2.662 ** \\
\hline English-French & -0.509 & -0.385 & 0.651 & -0.462 & 0.575 \\
\hline English-Brazilian & $3.689 * * *$ & $1.917^{*}$ & -2.397 ** & $-3.154^{* * *}$ & 0.464 \\
\hline Portuguese-Spanish & 2.082 * & -0.192 & 1.594 & 1.053 & 1.646 \\
\hline Portuguese-French & 0.984 & 1.150 & 1.400 & -0.152 & -0.851 \\
\hline Portuguese-Brazilian & -3.379 ** & -1.116 & -1.528 & $-3.263^{* * *}$ & -0.919 \\
\hline Spanish-French & -1.199 & 1.482 & -0.176 & -1.196 & $-2.452^{* *}$ \\
\hline Spanish-Brazilian & $-5.452 * * *$ & -1.010 & $-3.271^{* * *}$ & $-4.088^{* * *}$ & $-2.467^{* *}$ \\
\hline French-Brazilian & $-4.563^{* * *}$ & $-2.608 * *$ & $-3.035^{* *}$ & $-3.116^{* *}$ & -0.109 \\
\hline
\end{tabular}


An analysis of online reviews by language groups: the case of hotels in Porto, Portugal.

superior hotel classes, suggests as expected that guests enjoy higher satisfaction levels in five-star hotels, and that satisfaction decreases in lower class hotels. Also, this decreasing rate is higher for Spanish ratings.

Our results show globally higher satisfaction by Brazilians but we suggest that more attention should be given to Spanish speakers. Spanish guests post more negative reviews, suggesting that hotels should pay more attention to them in terms of service, since a significant share of visitors to Porto are from Spain.

Also, confirming the results from Schuckert et al. (2015), Table 2 shows that, in general, lower class hotels (two and three stars) are more likely to generate a greater spread in ratings. That behavior is particularly present in the English and Spanish reviews. In terms of correlation, we can see in Table 3 that they are all significant and positive, albeit presenting low values around the 0.1-0.2 range. The results from the regression (Table 4) confirm the hypothesis of Melián-González et al. (2013) and show that an increase in the number of reviews has a significant impact on the average rating (e.g., the somewhat low coefficient implies that 100 more reviews increases the average rating by 0.043 ). This result is particularly interesting to the low-class hotels analyzed, since their lower average review ratings are also accompanied by a lower number of reviews. Also, and more interestingly, as the variance of review ratings decreases, the average rating tends to be higher, reflecting the higher variance observed in low-class hotels. This result implies that if a hotel gets a lot of mixed reviews its average rating is substantially lower. So, in order to counteract that effect, hotels managers need to encourage loyal customers to write reviews and at least respond to negative reviews. Testing for differences in total review ratings (Table 5 ), we conclude that there are no significant differences in mean values, except for Brazilians, who are consistently quite different from other travelers in their ratings. That difference is also significant across all hotel star levels and seems less robust when Brazilians are compared with Portuguese. We suggest that this general Brazilian idiosyncrasy deserves further attention in future research. Apart from the Brazilians, only Spanish guests present significant differences from English and French guests, and only in the two-star category.

\section{Conclusion}

This study contributes to the hospitality literature by revealing the differences in satisfaction between five different guest language groups across several hotel categories, in the city of Porto in northern Portugal. This study is of an exploratory nature, presenting some drawbacks that we intend to overcome in future research. Namely: i) we rely on secondary data and use a language criterion that does not distinguish between nationalities but only between the languages used in the reviews. Therefore, cultural issues related to different nationalities demand future research. For instance, the finding that Brazilian guests are generally different from the others deserves deeper investigation, focused particularly on cultural aspects; ii) our study is quantitative - we consider only the general classification posted by different users without looking at other factors (location, cleanliness, service, decoration, etc.) or analyzing the words used in each post, data which could provide relevant information. Guests may show significant satisfaction differences concerning those attributes that are sensitive issues in their country of origin; iii) due to the limited number of reviews for some hotels, we limited the number of analyzed reviews for each language and for each hotel to ten, yielding a sample that should ideally be larger and providing more robust results; iv) this study is only focused on Porto hotels, but it would be worthwhile to expand the analysis and study other significant Portuguese tourism destinations such as Lisbon, Algarve or Madeira. For instance, it would be interesting to know if the review behavior depends on the travel destination; v) finally, we have used only reviews from TripAdvisor. It would be interesting to compare these with other websites, especially because different nationalities tend to use different services, as happens with nearly every platform on the internet.

We conclude that Brazilian travelers tend to give higher ratings than other guests and Spanish travelers are at the other end of the spectrum. The former present consistently different average ratings when compared to the 
others and seem to be more satisfied with middle and superior class hotels, while Spanish guests are less satisfied with lower class hotels than any of the other language groups. Also, low class hotels are more likely to have differences in customer satisfaction, whereas an upgrade from a four to five-star hotel yields a slight boost in ratings. Our results suggest that hotel managers should use reviews to learn about their customers' experiences and reactions, as well as for providing the necessary feedback to guests, in particular to the more dissatisfied. The results also show the importance for hotels to promote greater customer participation in online review platforms and to create easier ways for customers to do so (e.g., discounts, points, etc.), because it results in a better average review rating. Naturally, hotel managers have to satisfy all kinds of guests but our results point out that special attention should be given to Spanish-speaking guests in all hotel classes, particularly in middle and low-class hotels. Due to the preponderance of Spanish tourists in the total number of travelers visiting Portugal, and Porto in particular, hotels should be more enthusiastic towards their Spanish guests, exerting more effort to satisfy them in order to obtain better online ratings.

\section{References}

Ayoun, B., Moreo, P. (2008) Does national culture affect hotel managers' approach to business strategy. International Journal of Contemporary Hospitality Management 32(1), 52-65.

Bansal, H., Voyer, P. (2000) Word-of-mouth processes within services purchase decision context. Journal of Service Research 3(2), 166-177.

Cantallops, A., Salvi, F. (2014) New consumer behavior: a review of research on eWOM and hotels. International Journal of Hospitality Management 36, 41-51.

Chaves, M., Gomes, R., Pedron, C. (2012) Analysing reviews in the web 2.0: small and medium hotels in Portugal. Tourism Management 33, 1286-1287.

Chen, R., Cheung, C., Law, R. (2012) A review of the literature on culture in hotel management research: what is the future? International Journal of Hospitality Management 31(1), 52-65.
Cox, C., Burgess, S., Sellito, C., Buultjens, J. (2009) The role of user-generated content in tourist' travel planning behavior. Jounal of Hospitality Marketing and Management 18(8), 743-764.

Gerdes, J., Stringam, B. (2008) Addressing researchers' quest for hospitality data: mechanism for collecting data from web resources. Tourism Analysis 13, 309-315.

Hsieh, A., Tsai, C. (2009) Does national culture really matter? Hotel service perceptions by Taiwan and American tourists. International Journal of Culture, Tourism and Hospitality Research 3(1), 54-69.

Huang, J., Huang, C., Wu, S. (1996) National character and response to unsatisfactory hotel service. International Journal of Hospitality Management 15(3), 229-243.

Huang, Y., Basu, C., Hsu, M. (2010) Exploring motivations of travel knowledge sharing on social network sites: An empirical investigation of U.S. college students. Journal of Hospitality Marketing and Management 19(7), 717-734.

Jeong, M., Jeon, M. (2008) Customer Reviews of Hotel Experiences through Consumer Generated Media (CGM). Journal of Hospitality and Leisure Marketing 17(1-2), 121-138.

Jiang, J., Gretzel, U., Law, R. (2014) Influence of Star Rating and Ownership Structure on Brand Image of Mainland China Hotels. Journal of China Tourism Research, 10(1), 69-94.

Lee, J., Park, D., Han, I. (2008) The effect of negative online consumer reviews on product attitude: An information processing view. Electronic Commerce Research and Applications 7(3), 341-352.

Lee, H., Law, R., Murphy, J. (2011) Helpful reviewers in TripAdvisor, an online travel community. Journal of Travel and Tourism Marketing 28(7), 675-688.

Limberger, P., Anjos, F., Meira, J., Anjos, S. (2014) Satisfaction in TripAdvisor.com: An analysis of the correlation between evaluation criteria and overall satisfaction. Tourism \& Management Studies 10(1), 5965.

Litvin, S., Goldsmith, R., Pan, B. (2008) Electronic word-of-mouth in hospitality and tourism management. Tourism Management 29, 458-468. 
An analysis of online reviews by language groups: the case of hotels in Porto, Portugal.

Lopes, R., Abrantes, J., Kastenholz, E. (2014) Innovation, tourism and social networks. Revista Turismo e Desenvolvimento 21/22, 151-154.

Lu, W., Stepchenkova, S. (2012) Ecotourism experiences reported online: Classification of satisfaction attributes. Tourism Management 33(3), 702-712.

Melián-González, S., Bulchand-Gidumal, J., López-Valcárcel, B. (2013) Online customer reviews of hotels: As participation increases, better evaluation is obtained. Cornell Hospitality Quarterly 54(3), 274-283.

O'Connor, P. (2010) Managing a hotel's image on TripAdvisor. Journal of Hospitality Marketing and Management 19(7), 754772.

Park, D., Lee, J. (2008) eWOM overload and its effect on consumer behavioral intention depending on consumer involvement. Electronic Commerce Research and Applications 7(4), 386-398.

Pavlou, P., Dimoka, A. (2006) The nature and role of feedback text comments in online marketplaces: implications for trust building, price premiums, and seller differentiation. Information Systems Research 17(4), 392-414.

Schuckert, M., Liu, X., Law, R. (2014) Hospitality and tourism online reviews: recent trends and future directions. Journal of Travel and Tourism Marketing 32(5), 608-621.

Schuckert, M., Liu, X., Law, R. (2015)A segmentation of online reviews by language groups: how English and nonEnglish speakers rate hotels differently. International Journal of Hospitality Management 48, 143-149.

Sparks, B., Browning, V. (2011) The impact of online reviews on hotel booking intentions and perception of trust. Tourism Management 32(6), 1310-1323.

Stringam, B., Gerdes, J. (2010) An Analysis of Word-of-Mouse Ratings and Guest Comments of Online Hotel Distribution Sites. Journal of Hospitality Marketing and Management 19(7), 773-796.

Stringam, B., Gerdes, J., Vanleeuwen, D. (2010) Assessing the importance and relationships of ratings on user-generated traveler reviews. Journal of Quality
Assurance in Hospitality \& Tourism 11(2), 73-92.

Tse, E., Ho, S. (2009) Service quality in the hotel industry when cultural contexts matter. Cornell Hospitality Quarterly 50(4), 460-474.

TTCl (2016), Travel \& Tourism Competitiveness Index 2015. World Economic Forum. Available at https://www.weforum.org/.

Vermeulen, I., Seegers, D. (2009) Tried and tested: The impact of online hotel reviews on consumer consideration. Tourism Management 30, 123-127.

Wilson, A., Murphy, H., Fierro, J. (2012) Hospitality and travel: The nature and implications of user-generated content. Cornell Hospitality Quarterly 53(3), 220228.

Xiang, Z., Gretzel, U. (2010) Role of social media in online travel information search. Tourism Management 31, 179-188.

Xie, H., Miao, L., Kuo, P.-J., Lee, B.-Y. (2011) Consumers' responses to ambivalent online hotel reviews: the role of perceived source credibility and pre-decisional disposition. International Journal of Hospitality Management 30, 178-183.

Ye, Q., Law, R., Gu, B. (2009) The impact of online user reviews on hotel room sales. International Journal of Hospitality Management 28, 180-182.

Ye, Q., Law, R., Gu, B., Chen, W. (2011) The influence of user-generated content on traveler behavior: An empirical investigation on the effects of eword-ofmouth to hotel online bookings. Computers in Human Behavior 27(2), 634639.

Yoo, K.-H., Gretzel, U. (2008) Use and impact of online travel reviews. In P. O'Connor, W. Hopken, U. Gretzel (Eds.), Information and Communication Technologies in Tourism 2008, 35-46. Vienna, Austria: Springer.

Zheng, T., Youn, H., Kincaid, C. (2009) An analysis of customers' e-complaints for luxury resort properties. Journal of Hospitality Marketing and Management 18(7), 718-729. 